\title{
Strength, Chloride Permeability and Corrosion of Coarse Fly Ash Concrete with Bagasse-Rice Husk-Wood Ash Additive
}

\author{
Veera Horsakulthai and Kittichat Paopongpaiboon \\ Department of Civil Engineering, \\ Faculty of Engineering, Khon Kaen University, Khon Kaen 40002, Thailand
}

Received 2012-11-21, Revised 2013-02-22; Accepted 2013-04-17

\begin{abstract}
This study studied the utilization of Bagasse-Rice Husk-Wood Ash (BRWA) as an additive for improving the strength and durability of coarse Fly Ash (FA) concrete. The ground BRWA was used as an additive for maintaining the consistent slump of FA concrete. The strength, chloride permeability and corrosion resistance were investigated. The chloride permeability of concrete was evaluated using the measurement of coulomb charge as per ASTM C1202 and the corrosion resistance was detected using the Accelerated Corrosion test by Impressed Voltage (ACTIV). The test indicated that the incorporation of ground BRWA as an additive in FA concrete improved potentially both the strength and corrosion resistance, particularly the concrete containing up to $40 \%$ FA. While the $60 \%$ FA concrete with ground BRWA additive improved significantly in strength, the resistance to corrosion was insignificantly improved. The results showed that the use of ground BRWA as an additive was one approach for its utilization in concrete beyond use as pozzolan. The increase in the use of BRWA in concrete could reduce costs and minimize the environmental problems as well.
\end{abstract}

Keywords: Coarse Fly Ash, Bagasse-Rice Husk-Wood Ash, Additive, Corrosion, Chloride Permeability, Compressive Strength, Current Passed

\section{INTRODUCTION}

The durability of reinforced concrete structures is important for a long life, which depends on the concrete's resistance to chemical attacks, physical impacts and the ability of the concrete to protect the reinforcing steel bars against corrosion. Chloride is a principal cause of reinforced steel corrosion in concrete structures. If the ingress of chloride ion into concrete concentrates exceeds a threshold value, the thin passive oxide film around the reinforcement is destroyed. In the presence of oxygen and moisture, the corrosion is then initiated.

Bagasse-Rice Husk-Wood Ash (BRWA) is a byproduct obtained from biomass power plants that use bagasse, rice husk and chopped wood and burn them to produce steam for generating electricity to supply the sugar mills. Most of the BRWA is disposed of as waste in landfill which causes environmental problems such as air pollution as well as groundwater quality issues owing to the leaching of metals from the ashes. As-received BRWA has a large particle size, an irregular shape, a highly micro-porous texture and a very high surface area, as shown in Fig. 1a. This results in a higher water requirement to maintain workability and a lower compressive strength. However, the BRWA is ground up into fine particles, which partially replaces cement to produce concrete, resulting in an improvement of its compressive strength. The incorporation of ground BRWA not only significantly enhances the strength but also markedly improves the resistance to corrosion. The optimum level of cement replacement is $20 \%$ by weight of binder (Horsakulthai et al., 2011).

Corresponding Author: Veera Horsakulthai, Department of Civil Engineering, Faculty of Engineering, Khon Kaen University, Khon Kaen 40002, Thailand 


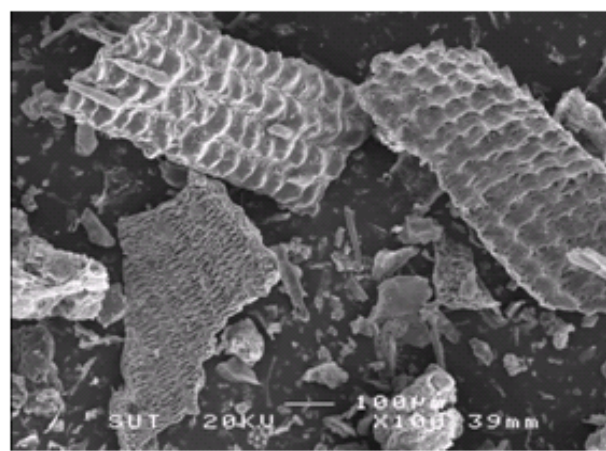

(a)

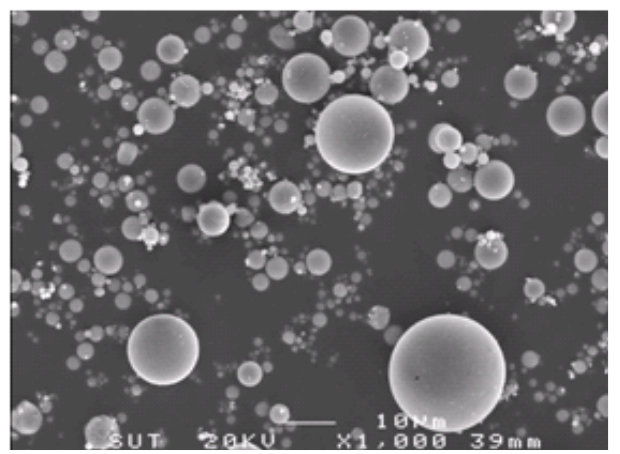

(c)

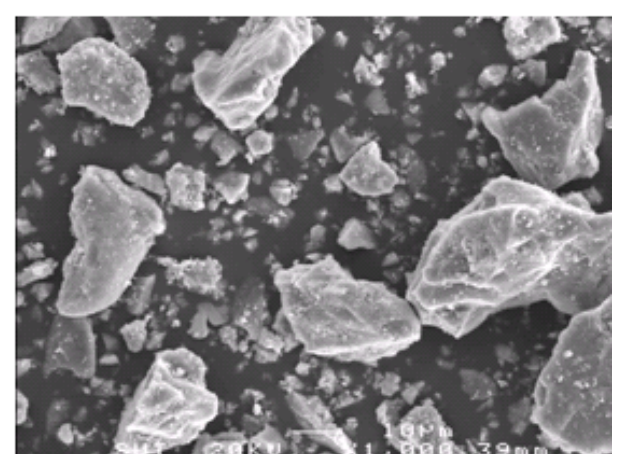

(b)

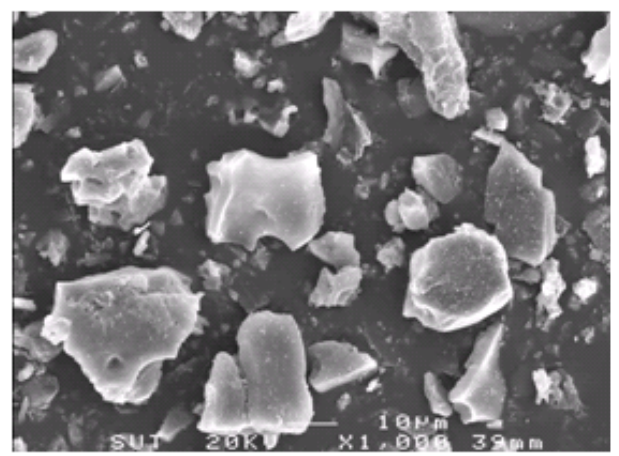

(d)

Fig. 1. SEM photo of PC, FA and BRWA, (a) As-received BRWA, (b) PC, (c) FA and (d) Ground BRWA

It is known that Fly Ash (FA) is a very common pozzolan, is a by-product of coal-burning electric power plants and is used worldwide in blended cements. The incorporation of FA results in the reduction of water demand and an increased workability of concrete can also be achieved due to its spherical shape and smooth surface (Peris-Mora et al., 1993; Jiang and Malhotra, 2000; Naik and Ramme, 1990). The low development of strength at an early age is a disadvantage of FA blended cement concrete, especially the cement replacements with a high amount of FA and/or coarse FA (Naik and Ramme, 1990; Gopalan, 1993; Erdogdu and Turker, 1998; Paya et al., 1995; Lia and $\mathrm{Wu}, 2005)$. In recent decades, their disadvantages have been improved by using ternary blended cement, which is combination of Portland Cement (PC), FA and other supplementary cementitious materials, namely, Silica Fume (SF), Rice Husk Ash (RHA), or Metakaolin (MK). The production of concrete with ternary blended PC, FA and SF not only compensates with early strength for the FA concrete, but the FA too enhances the strength development in the long term for SF concretes (Thomas et al., 1999). Furthermore, the ternary blended PC, FA and SF have been frequently attributed to synergistic effects taking place between each other, leading to a reduced average pore size of the paste and porosity of the interfacial transition zone between the paste matrix and the aggregates of concrete, thereby increasing the chloride impermeability (Radlinski and Olek, 2012; Poon et al., 1999; Wei et al., 2007; Shi et al., 2011). In addition, the use of ternary blended PC, FA and MK, or PC, FA and RHA results in an increase in strength and durability of the concrete (Wei et al., 2007; Shi et al., 2011; Mehta, 1988; Isaia, 1999; Bhanumathidas and Mehta, 2001).

The aim of this study is to improve the properties of coarse FA concrete for strength and corrosion resistance due to chloride ions. The ground BRWA is used as an additive materials to increase the fine fraction in concrete. The amount of ground BRWA used compensates for the water requirement of FA for maintaining similar workability when compared to plain concrete. The compressive strength, chloride permeability and corrosion resistance are investigated. The knowledge of the use of ground BRWA as an additive material to improve the strength and the resistance to corrosion of reinforced steel of the FA 
concrete will be beneficial for understanding the mechanism as well as for future applications of these materials beyond use as pozzolan in binary blended cement. Furthermore, it reduces in environmental problems and minimizes the requirement of landfill area to dispose of the BRWA.

\section{MATERIALS AND METHODS}

\subsection{Cement}

ASTM Type I Portland Cement (PC) was used. Its specific gravity and median particle size were 3.14 and $16.1 \mu \mathrm{m}$, respectively. The PC particles were irregular and crushed shape, as shown in Fig. 1b. The chemical compositions and gradation are given in Table $\mathbf{1}$ and Fig. 2, respectively.

\subsection{Fly Ash (FA)}

Lignite FA was a by-product obtained from the Mae Moh power plant in northern Thailand. The FA particles were spherical, solid shapes with a smooth surface, as shown in Fig. 1c. The chemical compositions and gradations are given in Table 1 and Fig. 2, respectively. It was rather coarse and contained large amounts of calcium oxide at $14 \%$. The median particle size, particle retained on sieve no. $325(45 \mu \mathrm{m})$ and specific gravity of FA were $38.7 \mu \mathrm{m}, 45 \%$ and 2.14 respectively. The sum of $\mathrm{SiO}_{2}, \mathrm{Al}_{2} \mathrm{O}_{3}$ and $\mathrm{Fe}_{2} \mathrm{O}_{3}$ and the LOI of FA were 76.5 and $0.6 \%$ respectively, complying with ASTM (1996-2013c) requirement for a class $\mathrm{F}$ pozzolan.

\subsection{Bagasse-Rice husk-Wood Ash (BRWA)}

BRWA is a by-product obtained from $82.5 \%$ bagasse, $15 \%$ rice husk and $2.5 \%$ chopped wood burnt together at temperatures ranging from 750 to $950^{\circ} \mathrm{C}$ to produce steam for generating electricity in power plants in northeastern Thailand. The BRWA was ground in a ball mill until the particles retained on sieve no. $325(45 \mu \mathrm{m})$ were less than $1 \%$. The chemical compositions and gradations are given in Table 1 and Fig. 2, respectively.

The ground BRWA had a median particle size of $10.5 \mu \mathrm{m}$ with $0.5 \%$ of particles retained on sieve no. 325 , while its specific gravity was 2.10 . The ground BRWA particle was irregular, with a crushed shape and its textures was slightly porous, as shown in Fig. 1d. From Table 1, the sum of $\mathrm{SiO}_{2}, \mathrm{Al}_{2} \mathrm{O}_{3}$ and $\mathrm{Fe}_{2} \mathrm{O}_{3}$ and the LOI of BRWA were calculated as 82.7 and $3.6 \%$, respectively, complying with ASTM C618 requirements for a natural pozzolan.

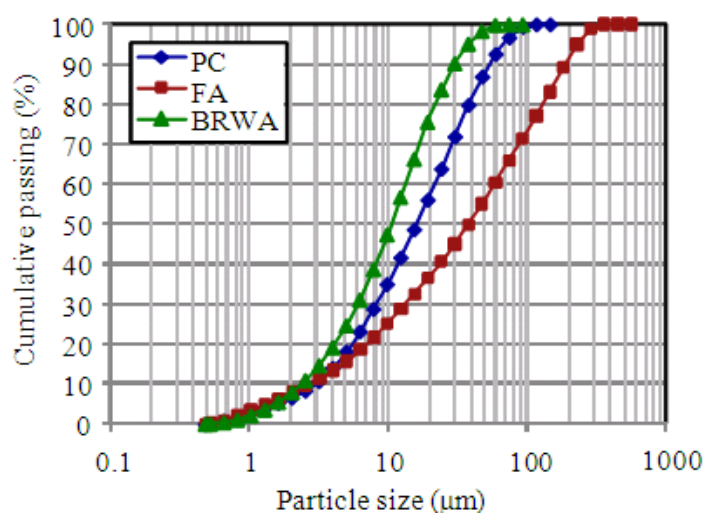

Fig. 2. Particle size distribution of PC, FA and ground BRWA

Table 1. Properties of PC, FA and BRWA

\begin{tabular}{lrrr}
\hline Chemical composition (\%) & \multicolumn{1}{c}{ PC } & \multicolumn{1}{l}{ FA } & BRWA \\
\hline $\mathrm{SiO}_{2}$ & 18.10 & 40.50 & 78.4 \\
$\mathrm{Al}_{2} \mathrm{O}_{3}$ & 4.20 & 23.70 & 2.6 \\
$\mathrm{Fe}_{2} \mathrm{O}_{3}$ & 3.70 & 12.30 & 1.7 \\
$\mathrm{CaO}$ & 68.30 & 14.00 & 7.4 \\
$\mathrm{MgO}$ & 1.30 & 2.90 & 1.3 \\
$\mathrm{Na}$ & 0.20 & 1.90 & 0.2 \\
$\mathrm{~K}_{2} \mathrm{O}$ & 0.40 & 2.60 & 3.7 \\
$\mathrm{SO}$ & 3.50 & 1.50 & 1.1 \\
$\mathrm{LOI}$ & 0.30 & 0.60 & 3.6 \\
$\mathrm{SiO}_{2}+\mathrm{Al}_{2} \mathrm{O}_{3}+\mathrm{Fe}_{2} \mathrm{O}_{3}$ & 26.00 & 76.50 & 82.7 \\
$\mathrm{Median}_{3}$ size, $\mathrm{D}_{50}(\mathrm{~mm})$ & 16.10 & 38.70 & 10.5 \\
Specific Gravity & 3.15 & 2.14 & 2.1 \\
\hline
\end{tabular}

\subsection{Aggregates}

$20 \mathrm{~mm}$ crushed limestone with a specific gravity of 2.77, a fineness modulus of 7.03, dry-rodded unit weight of $1,610 \mathrm{~kg} / \mathrm{m}^{3}$ and water absorption of $1.65 \%$ was the coarse aggregate used. Washed river sand with a specific gravity of 2.60 , a fineness modulus of 2.56 and water absorption of $0.65 \%$ was the fine aggregate used. Their gradations conformed to requirement of the ASTM (1996-2013a).

\subsection{Mix Proportions}

Normal strength concretes with a water-to-binder ratio $(w / b)$ of 0.50 were used. The Portland cement was partially replaced with FA at dosage of 20,40 and $60 \%$ by weight of binder. They were controlled in similar slumps ranging from $50 \mathrm{~mm}$ to $100 \mathrm{~mm}$. Two series of FA concretes with similar slumps were used; the first group was constituted of reduced water content and constant $w / b$; in the second group, ground BRWA was used as an additive for compensating the water requirements of the FA. The compositions of the concrete mixes are given in Table 2 . 
Table 2. Mix composition of concretes with $\mathrm{w} / \mathrm{b}$ of 0.50

\begin{tabular}{llllllll}
\hline & \multicolumn{7}{c}{ Composition $\left(\mathrm{kg} / \mathrm{m}^{3}\right)$} \\
Mix & $\begin{array}{l}\text { Slump } \\
(\mathrm{mm})\end{array}$ & $\begin{array}{lllllll}- \\
\text { Cement }\end{array}$ & FA & BRWA & Sand & C. agg. Water \\
\hline PC & 80 & 380 & - & - & 767 & 1,037 & 190 \\
20FA & 65 & 288 & 72 & - & 783 & 1,037 & 180 \\
40FA & 70 & 210 & 140 & - & 772 & 1,037 & 175 \\
60FA & 95 & 136 & 204 & - & 770 & 1,037 & 170 \\
20FA-B & 80 & 304 & 76 & 32 & 697 & 1,037 & 190 \\
40FA-B & 60 & 228 & 152 & 48 & 650 & 1,037 & 190 \\
60FA-B & 70 & 152 & 228 & 67 & 593 & 1,037 & 190 \\
\hline
\end{tabular}

\subsection{Concrete Casting and Curing}

Cylinder concretes of $100 \mathrm{~mm}$ diameter and $200 \mathrm{~mm}$ height were cast in two layers, each layer was rodded 25 times with a10 $\mathrm{mm}$ diameter rod and vibrated by a vibrating table for $5 \mathrm{sec}$. After $24 \mathrm{~h}$, they were demoulded and cured in water till the period of testing.

\subsection{Compressive Strength Test}

The compressive strength test was conducted by crushing three cylindrical concrete specimens of $100 \mathrm{~mm}$ diameter and $200 \mathrm{~mm}$ height at 7 days, 28 days and 90 days in accordance with ASTM (1996-2013b). The average of the three tests at each period was reported.

\subsection{Rapid Chloride Permeability Test (RCPT)}

After 7 days, 28 days and 90 days, the cylindrical concrete specimens of $100 \mathrm{~mm}$ diameter and $200 \mathrm{~mm}$ height were cut into $50 \mathrm{~mm}$ thick slices. The two inner slices were prepared and preconditioned, as described in ASTM (1996-2013d). The prepared cylinders were set up as shown in Fig. 3 and a $60 \mathrm{v}$ direct current was applied across the cell. The current passed was measured every 30 min for $6 \mathrm{~h}$ and the total coulomb charges through at the end of $6 \mathrm{~h}$ were reported. The RCPT was performed in accordance with ASTM C1202. The coulomb charge report was an average of two tests at each period.

\subsection{Accelerated Corrosion Test by Impressed Voltage (ACTIV)}

Cylindrical concrete specimens of $100 \mathrm{~mm}$ diameter and $200 \mathrm{~mm}$ height with a centrally embedded rebar of $12 \mathrm{~mm}$ diameter and $200 \mathrm{~mm}$ length were subjected to impressed voltage test in accordance with NTB (1989). They were partially immersed in $3 \% \mathrm{NaCl}$ solution and the circuit was connected with the embedded steel being the anode and an external stainless steel sheet being the cathode by applying a constant $5 \mathrm{v}$ direct current, as shown in Fig. 4. The variation of current was recorded once a day until the concrete specimen initiated cracks.

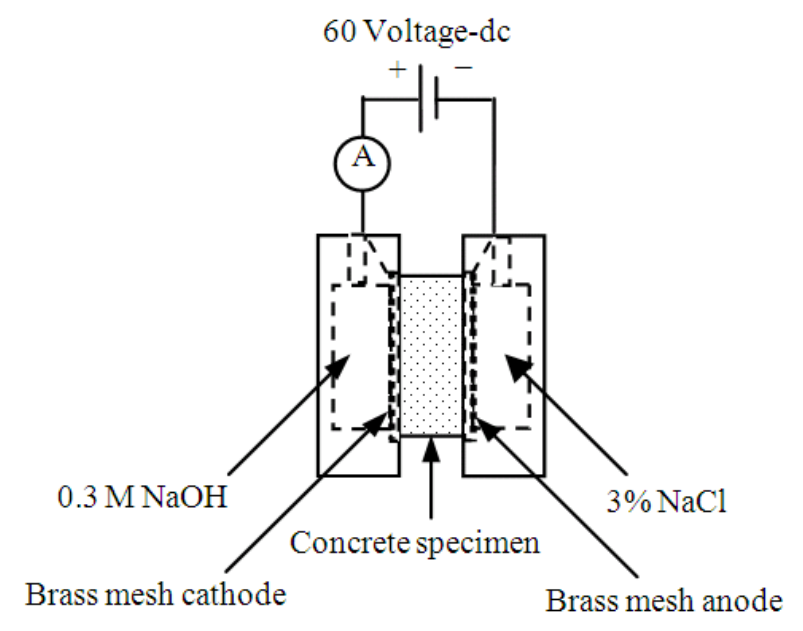

Fig. 3. RPCT test set up

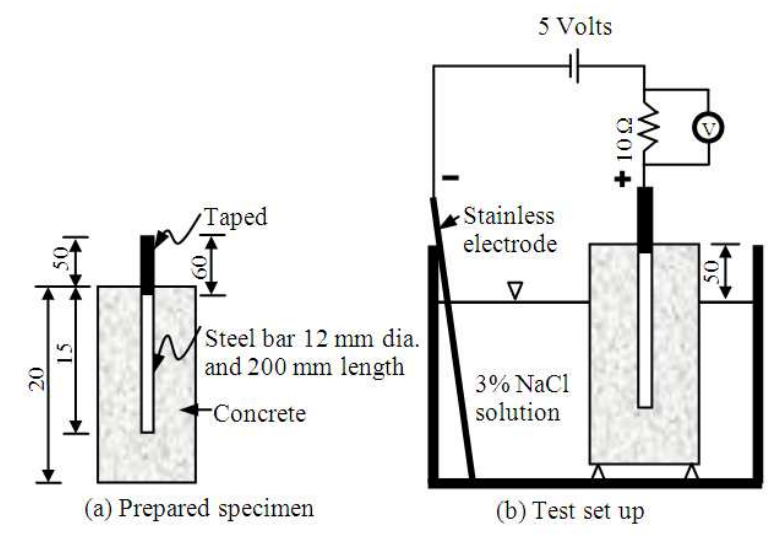

Fig. 4. Accelerated corrosion test by impressed voltage

\section{RESULTS AND DISCUSSION}

\subsection{Water Content and Ground BRWA Content}

A reasonable reduction in the water requirement of $\mathrm{FA}$ concrete was observed as the amount of FA increased in concrete with similar slumps. The water content of PC, 20FA, 40FA and 60FA was 190, 180, 175 and $170 \mathrm{~kg} / \mathrm{m}^{3}$, respectively. This resulted from the characteristics of FA, namely the spherical, solid shape and a smooth surface. On the contrary, the ground BRWA had a higher water requirement, which was used to compensate for the water requirement of the FA concrete.

The result of the mix proportion in Table 2 indicates that the increase in the amount of FA in the concrete resulted in the increase in the amount of the ground BWRA additive for maintaining similar slumps. The 
ground BRWA additive was added to the binder content at $8.5,12.5$ and $17.5 \%$ of the binder by weight for $20 \mathrm{FA}-$ B, 40FA-B and 60FA-B concrete, respectively.

\subsection{Compressive Strengths}

The effect of ground BRWA additive on the compressive strength of coarse FA concrete is given in Table 3. The compressive strength of PC concrete was $30.4,38.2$ and $45.5 \mathrm{MPa}$ at 7 days, 28 days and 90 days, respectively. The incorporation of the ground BRWA additive improved both the early and long-term strength of coarse FA concrete. At 7 days, the compressive strength of coarse FA concrete containing ground BRWA additive increased from 79.3 to 100.3 , from 60.9 to 76.3 and from 36.2 to $50.3 \%$ for $20 \mathrm{FA}, 40 \mathrm{FA}$ and 60FA, respectively, compared to the PC concrete. This was a reasonable increase in the compressive strength due to the effect of the fineness of the ground BRWA, which was higher than that of PC and FA, as shown in Fig. 2, to play the microfiller. The strength of FA concrete with the ground BRWA additive continuously increased during the period from 7 days to 90 days, with the normalized strength of $111,100.2$ and $73.8 \%$ for 20FA-B, 40FA-B and 60FA-B, respectively, whereas the normalized strength of 20FA, 40FA and 60FA was 95.4, 81.3 and $58.2 \%$, respectively. This indicated that both FA and the ground BRWA reacted with calcium hydroxide, obtained from cement hydration, to form a Calcium Silicate Hydrate (C-S-H) and the strength developed from the synergistic effect of FA and ground BRWA as well.

\subsection{Chloride Permeability}

As presented in Fig. 5, at the early stage of 7 days, the incorporation of the ground BRWA additive in the FA concrete insignificantly improved the resistance to chloride permeability, except in the mix of high volume FA concrete with $60 \%$ FA, which showed a marked reduction in the coulomb charge from 6,410 to 4,030 , or reduced by $37 \%$. The advantage of addition the ground BRWA additive showed potential at 28 days in that the coulomb charge reduced from 3,400 to 2,595 , from 1,845 to 1,530 and from 2,680 to 1,500 for the concrete containing 20, 40 and $60 \%$ FA, respectively. However, the FA concrete containing the ground BRWA additive insignificantly changed with respect to the coulomb charge for 40FA and 60FA at 90 days. The charge passed was about 465 coulombs to 625 coulombs, which was classified as a very low level of chloride ion penetrability, according to the ASTM C1202.

\subsection{Results of ACTIV}

\subsubsection{Initial Current and Time of Initial Crack}

The results of the initial current and the time of initial crack are presented in Table 4, Fig. 6-8. The initial current of PC concrete was $18.9 \mathrm{~mA}$ with the highest rate of current passed. After incorporating FA at dosages of 20, 40 and $60 \%$ (20FA, 40FA and 60FA, respectively), the initial current could be reduced to $18.0 \mathrm{~mA}, 12.1 \mathrm{~mA}$ and $12.3 \mathrm{~mA}$, respectively. There was a similar trend in chloride permeability in the total charge passed at 28 days, which was when immersion started. The decrease in the initial current was due to an increase in the electrical resistance due to the reduced pore size of the cement paste and decreased interfacial porosity, which made it difficult for the current passed to flow (Poon et al., 1999). The use of ground BRWA additive in the FA concrete was more effective in the increase in the electrical resistance, which resulted in the reduction of the initial current to $11.3 \mathrm{~mA}, 8.4 \mathrm{~mA}$ and $10.2 \mathrm{~mA}$, for 20FA-B, 40FA-B and 60FA-B, respectively.

The time of the initial crack of the PC concrete was the lowest at 26 days, in 20FA, 60FA and 40FA at 32 days, 36 days and 42 days, respectively. This conforms to the trend of the initial current. After adding the ground BRWA additive, the time of the initial crack of 20FA-B and 40FA$\mathrm{B}$ was increased to 74 days and 99 days, respectively. This was reasonable, considering the decrease of the initial current, but the 60FA-B inversely reduced the time of the initial crack to 33 days although the initial current was lower than that of 20FA-B and 60FA. This result might be because the strength of the passive film around the embedded steel was not adequately strong at 28 days.

\subsection{Characteristic of Corrosion Current of Concrete}

The relationships between the time of immersion and the current are presented in Fig. 6-8 from the investigation of the current at various times, it can be classified into three stages. An initial current decreased with time, which is the first stage. This could be attributed to the layer of passive iron oxide film which formed due to the reaction of cement and water. The passive film did not actually stop the corrosion, but reduced the corrosion rate to an insignificant level (ACI, 2001). At this stage, the initial current value depended on the transport property of the concrete, which is described by the charge passed and chloride diffusion coefficient. The second stage was started during a period of constant current value, except for relatively small current variations. 
Veera Horsakulthai and Kittichat Paopongpaiboon / American Journal of Applied Sciences, 10 (3): 239-246, 2013

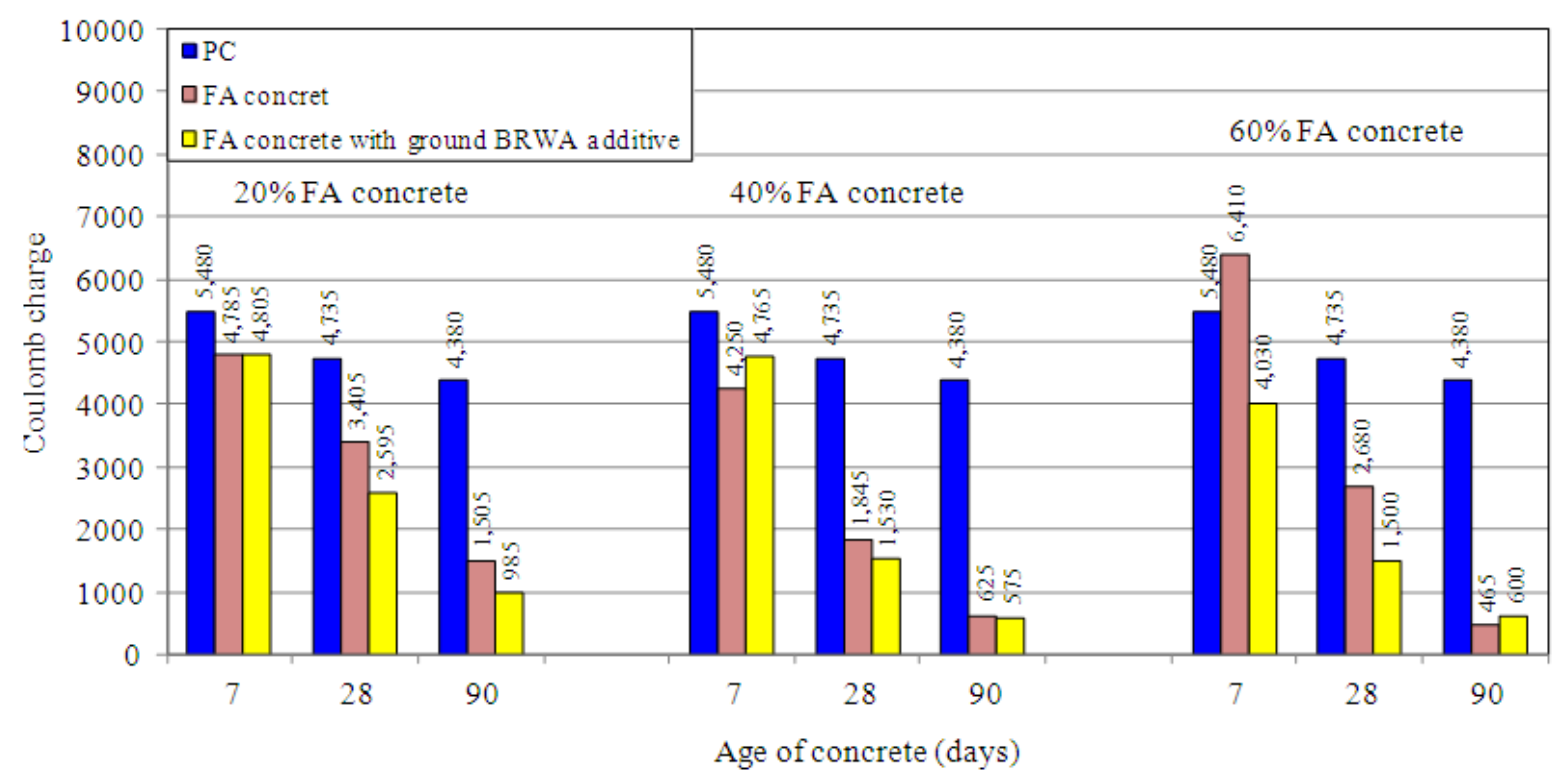

Fig. 5. Charge passed of concrete

Table 3. Compressive strength of concrete

\begin{tabular}{llll}
\multicolumn{4}{l}{ Table 3. Compressive strength of concrete } \\
\hline & Compressive strength (MPa)-Normalized \\
Mixes & - 7 days & 28 days & 90 days \\
\hline PC & $30.4-100$ & $38.2-100$ & $45.5-100$ \\
20FA & $24.1-79.3$ & $30.5-79.8$ & $43.4-95.4$ \\
40FA & $18.5-60.9$ & $25.0-65.4$ & $37.0-81.3$ \\
60FA & $11.0-36.2$ & $17.6-46.1$ & $26.5-58.2$ \\
20FA-B & $30.5-100.3$ & $38.8-102$ & $50.3-111$ \\
40FA-B & $23.2-76.3$ & $31.2-81.7$ & $45.6-100.2$ \\
60FA-B & $15.3-50.3$ & $21.0-55.0$ & $33.6-73.8$ \\
\hline
\end{tabular}

Table 4. Initial current and time of initial crack of concrete

\begin{tabular}{lcc}
\hline Mixes & $\begin{array}{l}\text { Initial } \\
\text { current }(\mathrm{mA})\end{array}$ & $\begin{array}{l}\text { Time of initial } \\
\text { crack (days) }\end{array}$ \\
\hline PC & 18.9 & 26 \\
20FA & 18.0 & 32 \\
40FA & 12.1 & 42 \\
60FA & 12.3 & 36 \\
20FA-B & 11.3 & 74 \\
40FA-B & 8.4 & 99 \\
60FA-B & 10.2 & 33 \\
\hline
\end{tabular}

The duration of this period was defined by the strength of the passive film and also the denseness of interfacial transition zone between the matrix and the reinforcing steel (ACI, 2001; Soylev and Francois, 2003). The third stage was when the current suddenly increased due to the microcrack initiated before the initial crack appeared. After this, the current continued to increase.

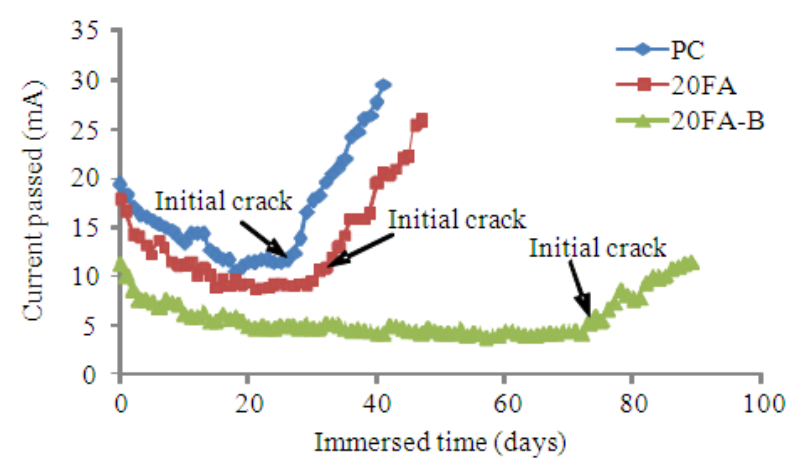

Fig. 6. Corrosion current of Concrete containing 20\% FA

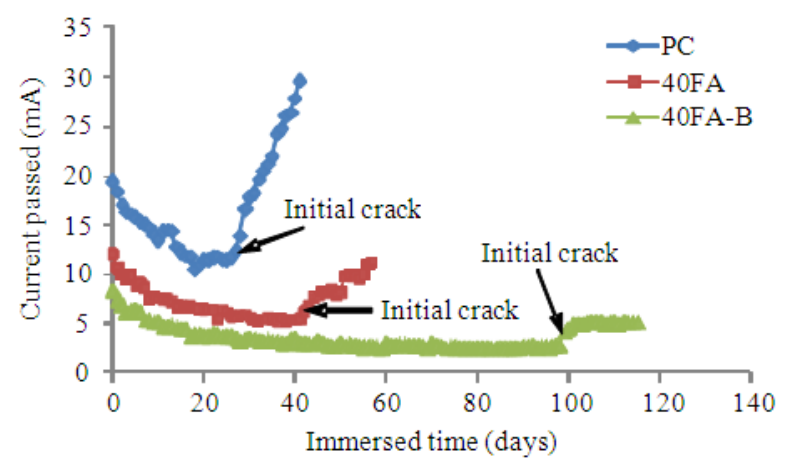

Fig. 7. Corrosion current of Concrete containing $40 \%$ FA 


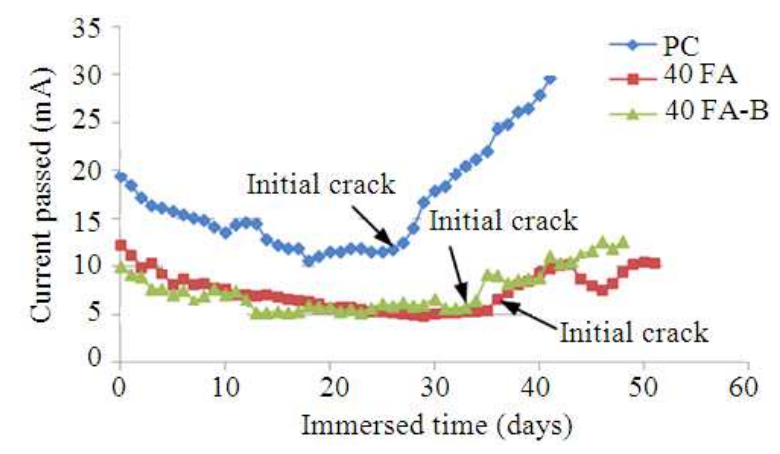

Fig. 8. Corrosion current of Concrete containing $60 \%$ FA

In this stage, the region of the passive film started to break down locally, then more chloride ions were attracted to this area and hence, the local concentration of the chloride ions increased and initiated corrosion, resulting in the sudden increase of current (NTB, 1989; ACI, 2001).

\section{CONCLUSION}

The following conclusions may be drawn based on the results obtained from this study:

- The use of ground BRWA as an additive in FA concrete improved both the early and long term strength. Furthermore, it could reduce the bleeding of FA concrete, particularly in high volume FA concrete

- The concrete containing up to $40 \%$ FA with the ground BRWA additive significantly improved in strength, chloride permeability and corrosion resistance compared to concrete with the same level of FA, while the concrete containing $60 \%$ FA with the ground BRWA additive only improved in strength, but the resistance to corrosion was insignificantly improved

- The use of ground BRWA as additive was one approach for its utilization in concrete beyond use as pozzolan. The increase in the use of BRWA could reduce environmental problems and minimize the requirements of landfill area to dispose of the BRWA

\section{ACKNOWLEDGMENT}

The researchers gratefully acknowledge the financial supports from the Research Fund of the Faculty of Engineering, Khon Kaen University. We also thank the Department of Civil Engineering, the Faculty of
Engineering, Khon Kaen University, for providing facilities and equipments.

\section{REFERENCES}

ACI, 2001. 222R-01: Protection of metals in concrete against corrosion (Reapproved 2010). American Concrete Institute.

ASTM, 1996-2013a. Standard specification for concrete aggregates. American Society for Testing and Materials (ASTM).

ASTM, 1996-2013b. Standard test method for compressive strength of cylindrical concrete specimens. American Society for Testing and Materials (ASTM).

ASTM, 1996-2013c. Standard Specification for Coal Fly Ash and Raw or Calcined Natural Pozzolan for Use in Concrete. American Society for Testing and Materials (ASTM).

ASTM, 1996-2013d. Standard test method for electrical indication of concrete's ability to resist chloride ion penetration. American Society for Testing and Materials (ASTM).

Bhanumathidas, N. and P.K. Mehta, 2001. Concrete mixtures made with ternary blended cements containing fly ash and rice-husk ash. Int. Concr. Res. Inform. Portal, 199: 379-391.

Erdogdu, K. and P. Turker, 1998. Effects of fly ash particle size on strength of Portland cement fly ash mortars. Cem. Concr. Res., 28: 1217-1222. DOI: 10.1016/S0008-8846(98)00116-1

Gopalan, M.K., 1993. Nucleation and pozzolanic factors in strength development of class fly ash concrete. ACI Mater. J., 90: 117-121.

Horsakulthai, V., S. Phiuvanna and W. Kaenbud, 2011. Investigation on the corrosion resistance of bagasserice husk-wood ash blended cement concrete by impressed voltage. Constr. Build. Mater., 25: 54-60. DOI: 10.1016/j.conbuildmat.2010.06.057

Isaia, G.C., 1999. Synergic action of fly ash in ternary mixtures of high-performance concrete. J. Sear. Res., 186: 481-502.

Jiang, L.H. and V.M. Malhotra, 2000. Reduction in water demand of non-air-entrained concrete incorporating large volumes of fly ash. Cem. Concr. Res., 30: 1785-1789. DOI: 10.1016/S00088846(00)00397-5

Lia, G. and X. Wu, 2005. Influence of fly ash and its mean particle size on certain engineering properties of cement composite mortars. Cem. Concr. Res., 35: 1128-1134. DOI: 10.1016/j.cemconres.2004.08.014 
Mehta, P.K., 1988. Role of flyash in sustainable development. Concr. Fly Ash Environ Proc.

Naik, T.R. and B.W. Ramme, 1990. Effects of high-lime fly ash content on water demand, time of set and compressive strength of concrete. ACI Mater. J., 87: 619-626.

NTB, 1989. Concrete, repairing materials and protective coating: Embedded steel method, chloride permeability. Nordic Innovation.

Paya, J., J. Monzo, E. Peris-Mora, M.V. Borrachero and R. Tercero et al., 1995. Early-strength development of Portland cement mortars containing air classified fly ashes. Cem. Concr. Res., 25: 449-456. DOI: 10.1016/0008-8846(95)00031-3

Peris-Mora, E., J. Paya and J. Monzo, 1993. Influence of different sized fractions of a fly ash on workability of mortars. Cem. Concr. Res., 23: 917-924. DOI: 10.1016/0008-8846(93)90045-B

Poon, C., L. Lam and Y. Wong, 1999. Effects of fly ash and silica fume on interfacial porosity of concrete. J. Mater. Civ. Eng., 11: 197-205. DOI: 10.1061/(ASCE)0899-1561(1999)11:3(197)
Radlinski, M. and J. Olek, 2012. Investigation into the synergistic effects in ternary cementitious systems containing Portland cement, fly ash and silica fume. Cem. Concr. Comp., 34: 451-459. DOI: 10.1016/j.cemconcomp.2011.11.014

Shi, X., Z. Yang, Y. Liu and C. Doug, 2011. Strength and corrosion properties of Portland cement mortar and concrete with mineral admixtures. Constr. Build. Mater., 25: 3245-3256. DOI: 10.1016/j.conbuildmat.2011.03.011

Soylev, T.A. and R. Francois, 2003. Quality of steelconcrete interface and corrosion of reinforcing steel. Cem. Concr. Res., 33: 1407-1415. DOI: 10.1016/S0008-8846(03)00087-5

Thomas, M.D.A., M.H. Shehata, S.G. Shashiprakash, D.S. Hopkins and K. Cail, 1999. Use of ternary cementitious systems containing silica fume and fly ash in concrete. Cem. Concr. Res., 29: 1207-1214. DOI: 10.1016/S0008-8846(99)00096-4

Wei, X., H. Zhu, G. Li, C. Zhang and L. Xiao, 2007. Properties of high volume fly ash concrete compensated by metakaolin or silica fume. J. Wuhan Univ. Technol., 22: 728-732. DOI: 10.1007/s11595006-4728-0 